Published in final edited form as:

Neurol Clin. 2009 August ; 27(3): 801-vii. doi:10.1016/j.ncl.2009.04.008.

\title{
Psychogenic Movement Disorders
}

\author{
Elizabeth L. Peckham, DOa, ${ }^{*}$ and Mark Hallett, MD $^{\mathrm{b}}$ \\ aNeurology Specialists of Dallas, 7515 Greenville Avenue, Suite 500, Dallas, TX 75231, USA \\ bHuman Motor Control Section, NINDS NIH, Building 10, Room 7D37, 10 Center Drive, MSC \\ 1428, Bethesda, MD 20892-1428, USA
}

\begin{abstract}
Keywords
Psychogenic movement disorder; Functional movement disorder; Conversion; Tremor; Medically unexplained symptoms; Dystonia
\end{abstract}

Psychogenic movement disorders (PMDs) represent a challenging dilemma for the treating neurologist. The terminology to classify this disorder is confusing and making the diagnosis is difficult. Once the diagnosis has been established, treatment options are limited, and the patient generally does not accept the diagnosis.

\section{DEFINITIONS}

The definition of PMDs is movement disorders caused by an abnormal psychiatric state, rather than an organic disorder of the nervous system. Psychogenic dystonia has been classified based on the level of certainty by Fahn and Williams. ${ }^{1}$ This classification is now widely accepted for other types of movements observed in PMDs.

\section{Documented Psychogenic}

Movements are persistently relieved by psychotherapy or psychological suggestion or with the administration of placebos. If the patient is observed to be symptom free when left alone, this may also be documented as psychogenic; however, this feature is usually indicative of malingering or factitious disorder.

\section{Clinically Established Psychogenic}

Inconsistent or incongruent with classical dystonia (on examination, the patient is unable to move the limbs but is able to dress herself in daily life). In addition, one or all of the following is highly suggestive: other neurologic signs present that are psychogenic (selfinflicted injuries, false weakness, false sensory findings), an obvious psychiatric disturbance is present, and multiple somatizations are present.

\footnotetext{
*Corresponding author. bethulrich@ @otmail.com (E.L. Peckham).
} 


\section{Probable Psychogenic}

Movements are inconsistent or incongruent, but there are no other features (as above) to further support the diagnosis. Movements are consistent with organic dystonia, but there are other features on examination to suggest psychogenicity (self-inflicted injuries, false weakness, false sensory findings). Multiple somatizations are present, but movements are consistent with organic dystonia.

\section{Possible Psychogenic}

An obvious emotional disturbance is present, but movements are consistent with organic dystonia.

Because of high diagnostic certainty, category a and $b$ have been combined to form a category called "clinically definite." 2 Shill and Gerber ${ }^{3}$ expanded this further with a designation of "clinically proven PMD," which requires remission when the patient is unobserved or with psychotherapy or when there is a premovement Bereitschaftspotential (BP) on electroencephalography (EEG) (for myoclonus only). Additionally, they created further criteria of PMD to include excessive pain or fatigue and previous disease exposure. ${ }^{3}$ The latter criterion presumably occurs as the nervous system mimics what it has previously seen. Extending the idea of Shill and Gerber that clinical neurophysiologic criteria can be used to secure the diagnosis, we propose that the category of "clinically proven PMD" could include such neurophysiologic tests or that a new category of "laboratory proven PMD" be considered.

Alternative terms for PMD are reported in the literature as a "functional" 4 movement disorder, "nonorganic"5 movement disorder, or as part of the spectrum of "medically unexplained symptoms."6

In the psychiatric literature, there are multiple terms that should be discussed as they relate to PMDs. These include conversion disorder, somatization disorder, factitious disorder, and malingering. These terms are classified in the Diagnostic and Statistical Manual of Psychiatric Disorders, Volume IV (DSM IV). ${ }^{7}$ The first category is somatoform disorders, and these include conversion disorder and somatization disorder. Conversion disorder is likely the most common mechanism of PMDs; it is defined as unexplained sensory or motor deficits that suggest a neurologic or other medical condition. Psychological factors are associated with symptoms. Somatization disorder is defined as a disorder beginning before the age of 30 years and extending over a period of years and consists of multiple conversion symptoms including "pseudo-neurological," gastrointestinal, pain, and sexual symptoms. Factitious disorders include intentional production of physical or psychological symptoms, where the goal is to assume the "sick role" and external incentives (financial, avoiding legal responsibility) are not present. In malingering, the symptoms can also be physical or psychological, but the individual is consciously aware of external incentives, and when the external incentives are removed, the symptoms resolve. An important distinction between conversion/somatoform disorders and factitious disorders/malingering is that conversion/ somatoform disorders are unconsciously produced, whereas factitious disorders/malingering are conscious. 


\section{PATIENT HISTORY}

Although the diagnosis of PMD was originally thought to be one of exclusion, ${ }^{1}$ there are many characteristics that define PMD as a positive entity (Table 1). When obtaining a neurologic history, it is important to look for these diagnostic features. Although there is no definite prototype PMD patient, most of these patients are women $(61 \%-87 \%)$, and average age is 44 years (range, $4-73$ years). ${ }^{8}$ In the history, the movements commonly occur as an abrupt onset and can be preceded by physical or emotional trauma. It is important to obtain a detailed psychosocial history, asking questions about stress, physical, emotional, or sexual abuse, substance abuse, and how the movements have affected interpersonal relationships. ${ }^{5}$ The movements themselves may also stop suddenly or have inconsistency over time. ${ }^{8}$ Interestingly, PMDs are commonly seen in patients in health care professions or allied health care professionals ${ }^{9}$ possibly due to the exposure to disease. Litigation or compensation for disability may be a factor in PMDs, and in one study this was found in 11 of $28(39 \%)$ of patients studied; ${ }^{10}$ such patients would be suspicious for malingering. Finally, underlying psychiatric disturbances are commonly seen in PMDs. The most common underlying psychiatric diagnoses are anxiety, depression, somatization, and conversion disorders. ${ }^{11}$ Underlying psychiatric diagnoses should be pursued by a psychiatrist who is familiar with PMDs, as this can aid in treatment options. Although it is common to find a coexisting psychiatric diagnosis with PMDs, it is important to note that psychiatric diagnoses are common with organic conditions as well. ${ }^{5}$

\section{PHYSICAL EXAMINATION FINDINGS}

In general, PMDs are characterized by an inconsistent character of movement (unusual presentation in amplitude, frequency, distribution), and they may increase with attention or decrease with distraction. ${ }^{9}$ Voluntary movements may appear slow, and patients may seem to struggle and put in more effort than needed to complete the task. ${ }^{11}$ Often, this is manifest by sighing, grimacing, and using their whole body to do a movement. The movements themselves may appear bizarre and should be incongruous with a known movement disorder. ${ }^{10}$ Observation is the most important tool for the neurologist looking for inconsistency of movements. However, several physical examination findings on routine neurologic examination may also suggest a psychogenic disorder: false weakness or give way weakness, false sensory loss, sensation that splits the midline, vibratory sense that splits the midline, and pseudo waxy flexibility. ${ }^{12}$ Several bedside tests that may be helpful in making a diagnosis of a PMD can be performed. First, the Hoover $\operatorname{sign}^{12}$ can be performed to look for psychogenic weakness. Testing is done with the patient laying supine and the heel of the weak leg in the examiner's hand. When the patient is asked to press the heel into the examiner's hand, there is no movement. Next, the opposite "strong" leg is flexed at the hip, and with counter pressure on this leg, hip extension is noted on the "weak" heel. An additional bedside test is the coactivation sign. ${ }^{12}$ During this test, the examiner palpates both agonist and antagonist muscles on strength testing. It may be easier to feel contraction of an antagonist muscle when the agonist muscle is tested (triceps activation when biceps muscle is being tested). On postural testing, bizarre or extreme responses may be present when the patient is pulled backward by the examiner. ${ }^{13}$ The "chair test" was described by Okun and colleagues $^{14}$ as a bedside test that may be helpful in patients with a psychogenic gait 
disorder. Patients are asked to walk 20 to $30 \mathrm{ft}$ forward and backward and then are asked to move a swivel chair the same distance by using their legs. In a study of 9 patients, 8 patients with a psychogenic gait were able to propel the chair forward and backward even though they had great difficulty with walking. These patients were compared with 9 control subjects with nonpsychogenic gait problems, and the control group had difficulty with both tasks.

\section{NEUROPHYSIOLOGY TESTING}

Neurophysiology testing in PMD is primarily helpful in distinguishing psychogenic tremor and myoclonus from organic forms of these conditions (Table 2). The main limitation with performing neurophysiology testing is that few laboratories in the United States have the capability to perform this technique, and it is time consuming. For psychogenic tremor, surface electromyograph (EMG) is placed over the muscles involved in tremor. Standard muscles used may involve biceps, wrist flexors, thenar, and anterior tibialis muscles bilaterally to record the frequency, amplitude, and duration of tremor. ${ }^{15}$ The basic protocol for testing patients uses a rest condition (tremor evaluated at rest with hands in the lap), a postural condition (arms are outstretched), a kinetic position (finger to nose testing), weighting conditions (using small wrist weights over the most affected hand), and testing of entrainment (tapping the opposite hand at a certain frequency to see if the tremor adopts that same frequency). ${ }^{16,17}$ Psychogenic tremor shows fluctuation in amplitude and frequency and disappearance of tremor when the patient is distracted. ${ }^{17}$ In one study, distractibility was formally tested by having the patient perform serial sevens and with alternate finger tapping while the EMG was recorded. ${ }^{16}$ When compared with patients who had essential tremor (ET), PMD tremor showed disappearance of the movements when the patient was distracted, whereas in ET the movements continued. In addition, in this same study by Kenney and colleagues, ${ }^{16}$ patients were tested for suggestibility through the instruction that their tremor would decrease if a tuning fork was vibrated on the forehead and that the tremor should increase with hyperventilation. Both of these conditions of suggestibility were also statistically significant when compared with ET. Entrainment is generally a very good test, but there are problems. Entrainment is thought to be specific in patients with PMD; however, entrainment was not significantly different when ET and PMD patients were compared by Kenney and colleagues. ${ }^{16}$ In another problem with the entrainment study, Zeuner and colleagues ${ }^{17}$ found that PMD patients were not very good at following the instruction for voluntary tapping, and this can make assessment tricky. For the weighting condition, tremor amplitude will often increase in psychogenic tremor, whereas it normally decreases or stays the same in organic forms of tremor. ${ }^{18}$ In a study by O'Suilleabhain and colleagues, ${ }^{15}$ PMD tremor involved fewer limb segments and fewer limbs than those in ET and Parkinson tremor. Further, in organic forms of tremor, there are thought to be multiple oscillators present, resulting in different frequencies of tremor in different limbs. This is in contrast to PMD where there appears to be a single oscillator. A bedside test that can be helpful with the simultaneous use of surface EMG is to have the patient perform a contralateral fast ballistic movement. In Kumru and colleagues, ${ }^{19}$ this was found to cause cessation of contralateral tremor oscillations or a significant decrease in amplitude when compared with ET and Parkinson's disease patients who had no change. 
Psychogenic myoclonus can also be distinguished from organic myoclonus with the help of electrophysiology. Evaluation of the patient is performed in the same way as the evaluation of tremor with surface EMG over the corresponding muscles that produce jerks. Organic myoclonus is characterized by burst length of less than $70 \mathrm{~ms}$, and jerks lasting longer than that are suggestive of a psychogenic etiology. ${ }^{20}$ In addition, if a triphasic pattern of agonist/ antagonist muscles is found, this is also suggestive of PMD. An additional technique that can be used to help distinguish organic from psychogenic myoclonus is EEG backaveraging. This technique is performed by backaveraging epochs of EEG and correlating this with the jerks recorded on surface EMG. In most normal subjects, a voluntary movement is preceded electrophysiologically by a premovement potential, the BP. ${ }^{20}$ In patients with psychogenic myoclonus, there is a BP-like slow EEG shift before the jerk. ${ }^{21}$ BPs are never recorded in organic involuntary movements. In the absence of a BP, it is not possible to exclude a psychogenic etiology, as the BP can be absent in normal subjects. Although, PMDs are thought to be involuntary, by this measurement, they follow more of a voluntary motor pathway. In addition, with EEG the presence of a large somatosensory potential or a brief cortical correlate of myoclonus is indicative of organic disease. ${ }^{22}$

\section{WORKUP}

The diagnosis of PMDs was originally thought to be one of exclusion. ${ }^{1}$ However, it is better to make a positive diagnosis based on the defining characteristics as discussed above. There is no standard workup for PMDs, and if suspected, the patient should be evaluated by a specialist with expertise in these conditions. The history and physical examination findings should be the main factors in making this diagnosis, and diagnostic testing should be used primarily to give further support to the underlying clinical suspicion that it is psychogenic. Magnetic resonance imaging can be helpful for excluding an underlying structural or demyelinating lesion. Blood work to include thyroid function, renal and liver function, and evaluation for Wilson's disease ${ }^{11}$ may be helpful. Neurophysiology studies to evaluate tremor and myoclonus can aid in the diagnosis as discussed earlier.

\section{TYPES OF PMD}

\section{Psychogenic Tremor}

Psychogenic tremor represents the majority of PMD, up to 55\%, and is present between $2 \%$ and $4 \%$ of patients seen in movement disorder clinics. ${ }^{11,23}$ The majority of cases are women, and, in one large study of PMD, tremor average duration was 4.6 years, and the average age was 43 years ( \pm 14 years). ${ }^{11}$ Clinical sites affected include the hand $(84 \%)$, the leg $(28 \%)$, and generalized body tremor $(20 \%) .{ }^{8}$ Common clinical characteristics on history that help differentiate it from organic tremors include sudden onset, unusual combination of rest and postural tremor, decrease with distraction, multiple associated somatizations, and spontaneous remission. ${ }^{24,25}$ As in other PMDs, the course is usually abrupt in onset (73\%), followed by either a static course (46\%) or fluctuating course (17\%). ${ }^{26}$ The frequency of the tremor is between 4 and $10 \mathrm{~Hz},{ }^{27}$ and neurophysiology studies as described here may be very helpful in making the diagnosis. Clinically, absence of finger tremor can be a positive diagnostic sign for psychogenic tremor. ${ }^{11}$ The underlying mechanism is largely unknown but may represent an underlying clonus mechanism in some patients. ${ }^{25}$ Another clinical 
manifestation seen in some patients is the coactivation sign, which can be appreciated by passively moving the affected oscillating joint and feeling for cocontraction of antagonist muscles in the affected limb. ${ }^{25} \mathrm{~A}$ recent study by Raethjan and colleagues ${ }^{28}$ suggests 2 possible mechanisms of psychogenic tremor based on an evaluation of 15 patients. Seven patients in the study showed coherent oscillations between the right and left hand, suggesting a voluntary-type mechanism; the other 8 patients showed independent oscillators suggestive of a clonus or physiologic tremor mechanism.

\section{Psychogenic Dystonia}

In most centers, psychogenic dystonia is the second most commonly encountered phenomenon except for one study by Columbia University where it was the most frequent. ${ }^{2}$ Historically, there are clues that point to a psychogenic etiology, including inconsistent dystonic movements over time, incongruous dystonic movements and postures, dystonia presenting as either a fixed or paroxysmal dystonia, and the presence of other bizarre involuntary movements to include a bizarre gait. ${ }^{1}$ Additional criteria include foot dystonia in an adult, resting dystonia, and contraction of antagonist with apparent action in agonist muscles, ${ }^{8}$ but none of these is specific. Organic dystonias should be suspected when there is a gradual onset with activity, and pain is not usually a feature despite contorted postures. ${ }^{9}$ In addition, there is a "dystonia-causalgia" syndrome described by Bhatia and colleagues, ${ }^{29}$ in which dystonia is induced by a peripheral injury. There is controversy about this in the literature, but the most recent study from Toronto Western Hospital involving 13 patients suggests a psychogenic etiology based on a suggestion of conversion disorder on the Minnesota Multiphasic Personality Inventory and resolution of most patients' symptoms with a sodium amytal interview. ${ }^{9}$ There are no physiologic tests available that readily distinguish psychogenic dystonia from organic dystonia. ${ }^{30}$

\section{Psychogenic Parkinsonism}

The true percentage of psychogenic Parkinsonism is not known, but it is thought to be relatively uncommon, representing only approximately $10 \%$ of PMDs. ${ }^{31}$ Typical features of organic Parkinsonism (decreased blink rate, axial rigidity, hypomimia) are typically absent in psychogenic Parkinsonism. ${ }^{32}$ Characteristic features in the tremor of psychogenic Parkinsonism include tremor of an abrupt onset that is present at rest and persists with posture and action. ${ }^{9}$ In accordance with other forms of psychogenic tremor, the tremor of psychogenic Parkinsonism will increase with attention and decrease with distraction and concentration. ${ }^{8}$ True rigidity and "cogwheel" phenomenon are not present, and, instead, there is passive resistance felt against the examiner. Slowness does not show the true decremental response found in organic Parkinsonism but instead is slow and effortful, often with whole-body movement to try and complete the task. ${ }^{13}$ On postural stability testing, patients may have bizarre responses including flailing of the arms and reeling backward without falling. ${ }^{8}$ Electrophysiology studies can be helpful in distinguishing a Parkinson's psychogenic tremor from other forms of tremor as outlined here. Neuroimaging can be helpful in establishing a diagnosis of psychogenic Parkinsonism. Loss of dopamine nerve function seen in organic Parkinsonism can be measured by decreases in dopamine transporter density or presynaptic dopamine deficiency (I 123 B-CIT) on single positron 
emission computed tomography (SPECT). ${ }^{31,33}$ In psychogenic Parkinsonism, these features are absent.

\section{Psychogenic Gait}

Disorders of gait and balance are commonly seen in psychogenic patients and represent $8 \%$ to $10 \%$ of all PMDs. ${ }^{34}$ Psychogenic gait disorders have been described since the late 1800 s, and the term astasia-abasia, meaning inability to stand and walk was used together in a paper describing gait disorders by Paul Blocq. ${ }^{35}$ During World War I, Roussy and Lhermitte further classified "hysteric gait disorders" into several subtypes: astasia-abasia, pseudotabetic, pseudopolyneuritic, tightrope walker, robot, habitual limping, choreic, knockkneed, as on a sticky surface, and as through water. ${ }^{36}$ At the present time, certain characteristics are evaluated on the physical examination to help define a psychogenic gait disorder. In one study by Lempert and colleagues, ${ }^{37} 6$ key features were identified in $97 \%$ of 37 patients through a videotape analysis. These included momentary fluctuation of gait and stance, excessive slowness, psychogenic Rhomberg, uneconomic postures, walking on ice, and sudden buckling of knees without falls. In another study by Baik and Lang, ${ }^{38} 279$ videotapes were analyzed, and patients with PMD both with and without gait abnormalities were compared. Of those PMD patients with a gait abnormality, excessive slowness, buckling of the knees, and astasia-abasia were the most common findings.

\section{Psychogenic Myoclonus}

Myoclonus represents between $8.5 \%$ and $19 \% 10,32,39$ of all PMDs depending on the center cited. In a study by Monday and Jankovic, ${ }^{39} 18$ patients were diagnosed with psychogenic myoclonus based on movements that were inconsistent with organic myoclonus and had at least 2 of the following features: decrease in movements with distraction, periods of remission, acute improvement, response to placebo, presence of other psychogenic symptomatology, and evidence of psychopathology by past psychiatric testing or by history. Myoclonus is described as brief, shock-like movements that are caused by muscle contractions arising from the central nervous system. ${ }^{8}$ In general, the frequency and amplitude varies little over time, the myoclonus remains in 1 body region (except in essential myoclonus), decreases with rest/sleep, worsens with distraction, and rarely remits. ${ }^{24}$ Features of psychogenic myoclonus included continuously changing pattern, frequency, amplitude, and anatomic distribution. ${ }^{39}$ Electrophysiology studies can be helpful in the evaluation of psychogenic myoclonus as described in the section on neurophysiology testing.

\section{TREATMENT}

Treatment begins when the physician has made the diagnosis and is ready to explain PMD to the patient (Fig. 1). This is a crucial first step, as it will directly influence whether the patient is accepting of the diagnosis and is willing to try an approach at treatment or whether he or she continues to seek further medical attention, convinced that there is something else really going on. It is advisable to discuss this diagnosis with the patient after several office visits, where a patient-physician relationship can be developed and after appropriate testing can be performed to help support the diagnosis. Reassurance is very important early on, 
emphasizing that the main components of the neurologic examination are "normal" and suggesting that the corresponding anatomy is also normal. In our experience, it is important to emphasize to the patient that this is an "involuntary" condition and is most likely the result of malfunctioning neural pathways. We often discuss that the exact cause of what is going on is unknown, but there may be environmental triggers (stress, physical trauma) that have helped precipitate the movements. From there, we usually discuss that there have been treatments found to be helpful and the best approach is to have the neurologist work in conjunction with a psychiatrist who understands PMDs. This is extremely important, as sending a patient to a psychiatrist without this understanding can result in the patient being sent back to you stating that he or she is not psychogenic. This will cause your patient to lose trust and faith in your diagnosis. Medication treatment can be initiated, and other supportive treatments can be added as well (rehabilitation, psychology) depending on the patient and the movements involved. If the patient is young and has a short duration of symptoms, we emphasize these key points stating that these are good prognostic factors. A question often asked by patients is "What do I tell my friends and family." The best approach to this question is for the patient to tell the family that he or she has a neurologic condition that produces involuntary movements and the cause is not well understood, but they are undergoing medical treatment to try and help the symptoms. We always introduce the term psychogenic; however, we prefer the term functional, as it is more accepted by the patient in general. The term psychogenic has an underlying implication to patients that they are doing this on purpose and it is all in their head. In a study by Stone and colleagues ${ }^{40} 102$ general neurology patients were asked which term they preferred when given the choice of pseudoseizures, nonepileptic attack disorder, psychogenic seizures, stress-related seizures, or functional seizures and patients felt that the terms stress-related seizures and functional seizures were less offensive and on par with the term tonic-clonic seizure.

Large randomized studies in patients with PMD are lacking, and evidence for treatment is largely based on retrospective, case control, and case report studies. Treatment can first be divided into inpatient versus outpatient treatment and further by classification of treatment to include medication, rehabilitation, cognitive behavioral therapies, biofeedback, hypnosis, placebo trials, and acupuncture.

\section{Inpatient Treatment}

Inpatient treatment is an option used at specialized centers in Canada and England and consists of a team approach. Patients are admitted for weeks to several months and followed by neurologists, psychiatrists, psychologists, physiatrists, and possibly therapists trained in alternative types of treatments. By far, the highest success rate is reported for resolution of symptoms with this type of technique. In a case series of 32 patients, $81 \%$ reported resolution of symptoms after a hospital stay of 1 week to 6 months. ${ }^{41}$ The remaining $19 \%$ of patients had partial resolution of symptoms. Inpatient treatment is not a feasible option for treatment in the United States due to insurance restrictions, and, thus, few centers in the United States have this capability. In these centers, stay is usually much shorter (1-2 weeks). Because of this, treatment is largely aimed at involving the same physicians and therapists in an outpatient setting. 


\section{Outpatient Treatment}

Oral medications-In a study by Voon and Lang, ${ }^{42} 23$ patients were identified with PMD, and 15 patients agreed to be treated with antidepressant medications. Of the 15 patients, 10 were diagnosed with primary PMD, and the remaining 5 were diagnosed with PMD and another somatoform disorder. Patients were treated with either paroxetine or citalopram and titrated up to an optimal dose during 4 weeks. Those who did not respond were switched to venlafaxine. Of the primary PMD patients, $80 \%$ ( 8 patients) had marked improvement, and 7 patients had complete remission. None of the 5 patients with PMD and other somatoform disorders improved. Notably, all of the primary PMD patients had concurrent underlying anxiety or depression, whereas only 2 of the 5 (40\%) patients with PMD and other somatoform disorders had an underlying psychiatric disorder.

Neuroleptic medications have also been reported to be of benefit for patients with conversion disorder. In a study by Rampello and colleagues, ${ }^{43} 18$ patients were treated-6 with haloperidol and 12 with sulpiride (not available in United States). The sulpiride group showed remarkable improvement in 8 patients, partial improvement in 2 patients, and no improvement in 1 patient. The haloperidol group showed 1 patient with remarkable improvement, 3 with partial improvement, and 2 with no improvement. The mechanism believed to account for improvement was thought to be secondary to the inhibition of the D2 dopamine receptor subtype that induces a large increase in prolactin secretion. Prolactin levels were followed in these patients and were found to be higher in the sulpiride group versus the haloperidol group. There is also a case report of a patient who was treated with risperidone for psychogenic stiff neck. ${ }^{44}$ The patient was previously tried on antidepressants, other neuroleptics, and antiepileptic medications with no benefit. Initially, she was placed on a combination of sertraline and risperidone, and the symptoms disappeared completely after 6 months of treatment with risperidone alone.

Behavioral modification-Shapiro and Teasell ${ }^{45}$ had a case series of 39 consecutive patients with conversion disorder who were admitted to an inpatient rehabilitation unit for treatment. All patients were told that they had a musculoskeletal problem that could resolve completely if they had an organic etiology. If the patients did not improve after 4 weeks, then they were told that it was a psychiatric condition, and the treatment would be modified to help them improve completely. If they did not improve, then they were given a final diagnosis of conversion disorder, and they were told that they could not improve because of an unconscious need to remain disabled. In 8 of 9 patients with acute conversion disorder (symptoms $<2$ months), the treatment was successful. In 1 of 28 chronic ( $>6$ months duration) patients, behavioral treatment was successful.

Psychotherapy of a more standard variety is likely the most common method for psychiatric intervention. Cognitive behavioral therapy is currently the most popular method for dealing with conversion disorders.

Physical therapy-A case series of 3 patients were treated in an inpatient setting where patients underwent behavioral modification treatments and shaping techniques for a maximum of 9 days of treatment. ${ }^{46}$ Specifically, correct patterns of movements were 
praised, and abnormal movements were ignored. All 3 patients had complete resolution of symptoms ${ }^{46}$ In addition, a retrospective study by Speed ${ }^{47}$ was performed in 10 patients with psychogenic gait. Patients were treated with physical therapy, occupational therapy, and recreational therapy, and psychological interventions were used in appropriate cases. All patients were able to ambulate normally (mean, 11.8 days) before discharge.

Biofeedback-There is 1 published abstract report where EMG biofeedback was used as a treatment for psychogenic tremor. ${ }^{48}$ In this study, 15 patients were trained over several sessions to decrease EMG signals associated with involuntary movements. Treatment was successful in 9 patients $(60 \%)$.

Hypnosis-In a randomized, controlled clinical trial, 44 patients with somatization disorder with motor conversion symptoms and conversion disorder, motor type, were assigned to a control (waiting list) group or an experimental (hypnosis) group in an outpatient setting. ${ }^{49}$ Patients were told at the beginning that either treatment was equally effective. Treatment consisted of 10 weeks of 1-hour hypnosis sessions, and the experimental group was improved compared with the control group. Improvement was maintained at a 6-month follow-up. Two additional studies used hypnosis in an inpatient setting. In one study, 8 patients with conversion disorder were treated for an average stay of 2 months (range, 1 week- 6 months) with hypnosis, and 7 of 8 subjects showed improvement or resolution of symptoms. ${ }^{50} \mathrm{~A}$ second study followed 45 patients with a multidisciplinary approach to treatment using a nurse, group therapist, creative therapy therapist, sports therapist, and physiotherapist. Approximately half of these patients were randomized to an additional treatment of hypnotherapy. Both groups had beneficial results, and there was no statistical difference in the group that had the addition of hypnosis.

Acupuncture-There is 1 case report that describes a dramatic response to acupuncture in a patient with chronic, treatment-resistant PMD. ${ }^{51}$ There have been no formal clinical trials or case control series of acupuncture.

Transcranial magnetic stimulation-There have been 3 recent clinical reports where transcranial magnetic stimulation (TMS) was used in psychogenic conditions. In a case report in 2009, Chastan and colleagues ${ }^{52}$ reported using 2 sessions of repetitive TMS (rTMS) in a patient with psychogenic dysphonia. The first session was performed over the left prefrontal cortex with no effect, and the second session, over the right motor cortex with immediate and dramatic improvement. Additionally, in Germany, rTMS was used in 8 patients with psychogenic tremor as a distraction technique. ${ }^{53}$ In this group, 4 patients responded, 2 showed temporary improvement, and 2 did not respond. The hypothesis from this study was that responders to rTMS were more inclined to see the reversibility of the disorder and thus were amenable to psychiatric treatment.

Trial of placebo-There is one case report where a patient with psychogenic blepharospasm (not responsive to botulinum toxin) improved through placebo. ${ }^{54}$ It was suggested that she would have improvement with a placebo medication and that if she did not improve then the cause was psychiatric and she would need to see a psychiatrist. This 
patient was a minor and it was done with parental consent. At this time, a placebo trial, without informed consent, is considered unethical.

\section{PROGNOSIS}

Reports are variable in terms of prognosis, but, in general, prognosis for patients with PMDs is poor (Table 3 ). In one study by Feinstein and colleagues, ${ }^{55} 42$ patients were sampled by telephone interview after an average follow-up of 3.2 years from diagnosis, and $90 \%$ had persistence of involuntary movements. In this study, poor outcome was associated with psychiatric comorbidity of Axis I disorders, long duration of symptoms, and insidious onset of movements. An additional study in patients with functional unilateral sensory or motor weakness at an average of 12.5 years of follow-up from presentation showed the presence of symptoms in $83 \%$ of 42 subjects evaluated. One patient in this sample went on to develop multiple sclerosis after being thought to be psychogenic initially. Patients with sensory symptoms had statistically significant better outcomes and reported higher levels of physical functioning, social functioning, and less pain when compared with those with motor symptoms. Lower levels of physical functioning were reported with higher age at onset of symptoms. In a study by Thomas and colleagues, ${ }^{56} 228$ patients were evaluated by structured telephone interview, and $56 \%$ of patients reported improvement in symptoms, $21 \%$ reported no change, and $22 \%$ were worse after an average duration of 3.4 years' follow-up. In this study, poor prognostic factors were inconsistent movements, dissatisfaction with the physician, long duration of illness, positive history of smoking, and suggestibility. Good prognostic factors were good physical health, positive social life, patients' perception of receiving effective treatment by the physician, elimination of a stressor, comorbid diagnosis of anxiety, and attribution of a specific medication. In a study by McKeon and colleagues, ${ }^{23}$ 53\% (33 patients) with electrophysiologically confirmed psychogenic tremor responded to a follow-up questionnaire. After a median follow-up of 3.2 years, $64 \%$ of patients rated their disability as moderate severe, $27 \%$ had complete resolution of symptoms, and $9 \%$ reported mild unchanged symptoms. Of the patients who had resolution of symptoms, in $15 \%$ (5 patients) the resolution occurred spontaneously and in $12 \%$ (4 patients) it occurred after an intervention (1 with an antidepressant, 1 with psychology/rehabilitation, 1 with hypnotherapy, 1 with behavioral therapy). In a separate study by Crimlisk and colleagues ${ }^{57}$ of 64 patients with medically unexplained symptoms, $28 \%$ showed complete resolution of symptoms, $20 \%$ improved, $14 \%$ remained unchanged, and $38 \%$ worsened after 6 years of follow-up. In this group, 3 patients were misdiagnosed and did have an underlying neurologic disorder including paroxysmal hemidystonia, spinocerebellar ataxia, and myotonic dystrophy. Finally, much higher rates of improvement are reported in a follow-up study by Couprie and colleagues 58 in patients who were admitted to the hospital for an inpatient stay for treatment of conversion disorder. In this study, $56 \%$ of patients admitted had resolution of symptoms on discharge, and $90 \%$ remained resolved at a 4-year follow-up. Two patients (4\%) were misdiagnosed-1 with a stroke and 1 with multiple sclerosis. A common concern with diagnosing PMD is that an underlying diagnosis has been missed; however, recent reports as discussed here show a very low percentage of patients with a misdiagnosis. This is in contrast to a previous report by Slater and Glithero ${ }^{59}$ 
in 1965 in which more than half of patients diagnosed with "hysteria" were thought to be misdiagnosed.

\section{RESEARCH FINDINGS}

Research to date has been primarily aimed at patients with conversion disorder. There have been several imaging studies using functional magnetic resonance imaging (fMRI). In 1997, Marshall and colleagues ${ }^{60}$ studied 1 patient with left-sided paralysis secondary to a conversion disorder. Imaging was studied in 2 conditions: 1 when the patient prepared to move her leg and 2 when she moved the leg. There was activation of cerebral blood flow to the motor and premotor areas of corresponding hemispheres when she prepared to move the left (paralyzed leg), prepared to move the right (normal) leg, and when she moved the right leg. When she attempted to move the left leg, there was absence of blood flow to the right primary motor cortex, and, instead, there was activation of the right orbitofrontal and right anterior cingulate cortex. This suggested to the authors that these 2 areas inhibit prefrontal effects of the willed movement of the right primary cortex. Motor imagery has been an interesting tool in conversion disorder patients. In 2007, de Lange and colleagues ${ }^{61}$ studied 8 conversion paralysis patients using fMRI as the patients performed tasks of imagined movements with the affected and unaffected hands. Motor imagery of both hands recruited the same areas of the motor cortex; however, motor imagery of the affected hand recruited additional regions including the ventromedial prefrontal cortex and superior temporal cortex. This additional activation was thought to represent difficulty in deactivating these areas of the brain during motor imagery tasks. The authors proposed that their findings represented heightened self-monitoring of subjects with conversion paralysis, and they hypothesized that cognitive-behavioral therapy should therefore be beneficial. In 2008, de Lange ${ }^{62}$ studied 7 conversion paralysis patients with fMRI, and imagined actions of the affected and unaffected hands were either implicitly or explicitly instructed to the patient. For both of these tasks, the patient had to judge the laterality of a rotated drawing of a right or left hand. The drawings were presented in different directions from $0^{\circ}$ to $180^{\circ}$ and in palmar and dorsal orientations. In the implicit task, patients had to judge as fast and accurately as they could whether the drawing represented a right or left hand. For the explicit task, patients were told to imagine that the hand was their own and imagine moving their hand into the position on screen. They also had to determine whether it was a right or left hand. Implicit imagery yielded larger activation of the ventromedial prefrontal cortex and superior temporal cortex in the affected hand compared with the unaffected hand, but this difference between hands was not present during the explicit task. This suggests that implicit and explicit tasks have a different level of self-monitoring involved, and techniques aimed at using explicit tasks (such as hypnosis) may be a valuable tool for conversion paralysis patients. A study by Stone and colleagues, ${ }^{63}$ in 2007, compared 4 patients with conversion paralysis manifested as a weak ankle, and 4 normal control subjects using fMRI where subjects were instructed to move the affected limb. The control subjects were instructed to simulate weakness when moving the ankle. Both groups showed reduction in the level of activation in the motor cortex; however, the patient group showed additional activation of the basal ganglia, insula, lingual gyri, and inferior frontal cortex. This suggests that the 
conversion group were attempting to move with greater mental effort than the control subjects.

Research in positron emission topography by Spence and colleagues ${ }^{64}$ compared 3 subjects with psychogenic paralysis with 4 control subjects who feigned paralysis. Patients with hysteria showed evidence of hypoactivity of the dorsolateral prefrontal cortex (DLPFC), and feigners exhibited hypoactivity of the right anterior prefrontal cortex, which was statistically significant. Although the sample size was small, the suggestion from this was that the left DLPFC is involved in internal choice of action, and thus patients appear to think that they cannot do the task, but actually they cannot "will" the task.

A single-photon emission computed tomography (SPECT) study was performed on 7 patients (6 females, 1 male) using 99m EC-TCD who had unilateral loss of motor and/or sensory loss due to a psychogenic etiology. ${ }^{65}$ During the study, patients had a SPECT scan performed under three separate conditions: resting condition with the deficit present, with a vibrating tuning fork placed on both hands when the deficit was present, and 2-4 months after the deficit resolved. SPECT imaging showed a decrease in blood flow of the thalamus and basal ganglia contralateral to the deficit in the vibratory condition which normalized on scans performed once the patients' symptoms resolved. The authors conclude that this provides evidence of abnormalities in the sensorimotor pathways correlating with psychogenic neurological symptoms.

Additional research in conversion disorder has been performed by Roelofs and colleagues ${ }^{66}$ and has addressed the speed of motor initiation times and motor execution times based on timed tasks between 4 patients and 6 control subjects. Motor initiation tasks were statistically slower in patients than in controls, but motor execution times were not statistically different. From this study, an additional study was conducted in control subjects divided into 8 low and 9 highly hypnotizable control subjects. ${ }^{67}$ It was hypothesized that the highly hypnotizable subjects were similar to conversion disorder patients. All subjects had implicit and explicit motor task instructions while they were hypnotized so that their right arm was paralyzed. For the implicit task, the patients were shown a picture of a drawing of a left or right hand in different directions from $0^{\circ}$ to $315^{\circ}$ degrees and in palmar or dorsal orientations. They were instructed to say right or left as quickly and accurately as they could when shown the drawing. For the explicit task, patients were again shown the drawing of a right or left hand and were asked to mentally rotate their hands to the direction on screen without actually moving the hand and to say "yes" once the task was completed. On the implicit task, there was no significant difference in reaction time. On the explicit task, the reaction time of the highly hypnotizable subjects showed a significant increase per degree of rotation compared with the normal arm. The results suggest a similar mechanism in highly hypnotizable subjects and conversion disorder subjects. Previous research by Roelofs and colleagues ${ }^{68}$ compared 50 conversion disorder patients with 50 control subjects to evaluate the level of hypnotizability of each group. Conversion patients were significantly more susceptible to hypnotic suggestion than control subjects, and further, there was a significant correlation between the level of hypnotic susceptibility and number of conversion complaints. 
Finally, a case report in 2008 describes a patient with left sided conversion paralysis who was evaluated by TMS. ${ }^{69}$ When her symptoms were present, she had a normal, symmetric central conduction time in the upper and lower limbs, an asymmetric corticomotor threshold which was increased in the right hemisphere, and a small motor-evoked potential (MEP) over the left abductor hallucis muscle. The abnormal threshold can be explained either by decreased cortical or lower motor neuron (LMN) excitability. In this case, the mean amplitude of the F-waves was symmetric on both sides, thus the cortical asymmetry is most likely explained by decreased cortical excitability. TMS was repeated 1 month after the resolution of the patients' symptoms and was normal. In addition the MEP of the left abductor hallucis increased 10-fold with resolution of symptoms. The TMS findings of increased corticomotor threshold with preserved LMN excitability corresponding with the patient's paralysis are thought to represent inhibitory activation over the motor cortex. It is hypothesized that this represents a protective mechanism of the limbic system, but is difficult to draw any definite conclusion based on the findings of one patient.

\section{PSYCHOGENIC MOVEMENT DISORDERS IN CHILDREN}

PMDs are well characterized in the adult population, but there is little information on children with PMDs. Two recent articles on children with PMD have addressed this issue. In a study by Ferrara and Jankovic, ${ }^{70}$ medical records from 54 children with PMD were reviewed. This represented $3.1 \%$ of all children with movement disorders seen in the Baylor clinic over a 20-year period. Average age of diagnosis was 14.2 years, and there was a female preponderance in those older than 13 years, whereas the ratio of male to female was equal in those patients younger than 12 years. Children at highest risk for development of PMD were adolescent girls, and the youngest patient was 7 years old. The most common phenomenology of movement was tremor, followed by dystonia, myoclonus, gait disorder, convergence spasm, disrupted speech, athetosis, and situational apraxia of eyelid opening. Similar to the adult population, there was an immediate stressor found in $69 \%$ of patients. In addition, $52 \%$ of patients reported comorbid symptoms of anxiety, depression, or persistent irritability and $6 \%$ of patients had suicidal ideation. Of the patients, $91 \%$ had associated somatic complaints, such as, headaches, fatigue, abdominal discomfort, numbness, joint pain, blurred vision, and sleep disturbance. Disability was common, and academic performance was affected in $50 \%$ of patients; $24 \%$ of patients were home schooled due to their PMD. Further, 22\% of patients had unnecessary surgeries for their PMD or related symptoms. It was uncommon to find coexistent neurologic disorders in the patients, but psychiatric conditions were common. Over one-third of patients were described as perfectionistic and high achievers. In a similar study by Schwingenschuh and colleagues, ${ }^{71}$ 15 cases of children with PMD were reviewed, and the average age at diagnosis was 12.3 years; the youngest patient was 7 years old. Psychogenic dystonia (47\%) was the most common manifestation, followed by tremor (40\%) and gait disorder (13\%). In $40 \%$ of patients, a single movement was present, whereas in $60 \%$, multiple movement types were observed. In this study, there was a female preponderance by $4: 1$. In $80 \%$ of cases, the DSM IV diagnosis was conversion disorder, and the remaining $20 \%$ of cases were somatization disorder. In this review, $47 \%$ of cases recovered fully, $33 \%$ recovered substantially, and $20 \%$ remained substantially disabled. Good prognostic indicators were a short duration of 
illness ( $<1$ month), tremor, and an identifiable stressor that could be resolved. Childhood and adult PMDs appear similar in phenomenology and clinical characteristics and both carry a better prognosis with a shorter duration of illness. Similar techniques with a multidisciplinary approach have been used in both groups with some success.

\section{SUMMARY}

PMD patients have often proven difficult to identify, but well-defined characteristics in the history, examination, and physiologic testing are now making the task easier. However, there is very little research in this area, and evidence for beneficial treatment is lacking. Prognosis is usually poor, and most patients are left with a high level of disability. This is especially unfortunate, because this is one condition in neurology where it should be possible to completely reverse symptoms. This condition is truly a "crisis for neurology,"72 and further research should be dedicated to developing an algorithm for effective treatments.

\section{References}

1. Fahn S, Williams DT. Psychogenic dystonia. Adv Neurol. 1988; 50:431-55. [PubMed: 3400501]

2. Williams DT, Ford B, Fahn S. Phenomenology and psychopathology related to psychogenic movement disorders. Adv Neurol. 1995; 65:231-57. [PubMed: 7872143]

3. Shill H, Gerber P. Evaluation of clinical diagnostic criteria for psychogenic movement disorders. Mov Disord. 2006; 21(8):1163-8. [PubMed: 16685685]

4. Ehrbar R, Waespe W. [Functional gait disorders]. Schweiz Med Wochenschr. 1992; 122(22):83341. [in German]. [PubMed: 1604288]

5. Reich SG. Psychogenic movement disorders. Semin Neurol. 2006; 26(3):289-96. [PubMed: 16791775]

6. Crimlisk HL, Bhatia KP, Cope H, et al. Patterns of referral in patients with medically unexplained motor symptoms. J Psychosom Res. 2000; 49(3):217-9. [PubMed: 11110993]

7. American Psychiatric Association. Diagnostic and statistical manual of mental disorders DSM-IVTR. Washington, DC: American Psychiatric Association; 2000. American Psychiatric Association, task force on DSM-IV.

8. Thomas M, Jankovic J. Psychogenic movement disorders: diagnosis and management. CNS Drugs. 2004; 18(7):437-52. [PubMed: 15139799]

9. Miyasaki JM, Sa DS, Galvez-Jimenez N, et al. Psychogenic movement disorders. Can J Neurol Sci. 2003; (30 Suppl 1):S94-100. [PubMed: 12691482]

10. Factor SA, Podskalny GD, Molho ES. Psychogenic movement disorders: frequency, clinical profile, and characteristics. J Neurol Neurosurg Psychiatr. 1995; 59(4):406-12. [PubMed: 7561921]

11. Bhatia KP, Schneider SA. Psychogenic tremor and related disorders. J Neurol. 2007; 254(5):569_ 74. [PubMed: 17417745]

12. Stone J, Zeman A, Sharpe M. Functional weakness and sensory disturbance. J Neurol Neurosurg Psychiatr. 2002; 73(3):241-5. [PubMed: 12185152]

13. Lang AE, Koller WC, Fahn S. Psychogenic parkinsonism. Arch Neurol. 1995; 52(8):802-10. [PubMed: 7639632]

14. Okun MS, Rodriguez RL, Foote KD, et al. The "chair test" to aid in the diagnosis of psychogenic gait disorders. Neurologist. 2007; 13(2):87-91. [PubMed: 17351529]

15. O’Suilleabhain PE, Matsumoto JY. Time-frequency analysis of tremors. Brain. 1998; 121(Pt 11): 2127-34. [PubMed: 9827772]

16. Kenney C, Diamond A, Mejia N, et al. Distinguishing psychogenic and essential tremor. J Neurol Sci. 2007; 263(1-2):94-9. [PubMed: 17604055] 
17. Zeuner KE, Shoge RO, Goldstein SR, et al. Accelerometry to distinguish psychogenic from essential or parkinsonian tremor. Neurology. 2003; 61(4):548-50. [PubMed: 12939436]

18. Deuschl G, Koster B, Lucking CH, et al. Diagnostic and pathophysiological aspects of psychogenic tremors. Mov Disord. 1998; 13(2):294-302. [PubMed: 9539344]

19. Kumru H, Valls-Sole J, Valldeoriola F, et al. Transient arrest of psychogenic tremor induced by contralateral ballistic movements. Neurosci Lett. 2004; 370(2-3):135-9. [PubMed: 15488310]

20. Brown P, Thompson PD. Electrophysiological aids to the diagnosis of psychogenic jerks, spasms, and tremor. Mov Disord. 2001; 16(4):595-9. [PubMed: 11481681]

21. Shibasaki H, Hallett M. What is the Bereitschaftspotential? Clin Neurophysiol. 2006; 117(11): 2341-56. [PubMed: 16876476]

22. Schrag A, Lang AE. Psychogenic movement disorders. Curr Opin Neurol. 2005; 18(4):399-404. [PubMed: 16003115]

23. McKeon A, Ahlskog JE, Bower JH, et al. Psychogenic tremor: long term prognosis in patients with electrophysiologically-confirmed disease. Mov Disord. 2008; 24(1):72-6. [PubMed: 18831532]

24. Marjama J, Troster AI, Koller WC. Psychogenic movement disorders. Neurol Clin. 1995; 13(2): 283-97. [PubMed: 7643826]

25. Deuschl G, Raethjen J, Lindemann M, et al. The pathophysiology of tremor. Muscle Nerve. 2001; 24(6):716-35. [PubMed: 11360255]

26. Kim YJ, Pakiam AS, Lang AE. Historical and clinical features of psychogenic tremor: a review of 70 cases. Can J Neurol Sci. 1999; 26(3):190-5. [PubMed: 10451741]

27. Deuschl G, Bain P, Brin M. Consensus statement of the Movement Disorder Society on Tremor. Ad Hoc Scientific Committee. Mov Disord. 1998; (13 Suppl 3):2-23. [PubMed: 9827589]

28. Raethjen J, Kopper F, Govindan RB, et al. Two different pathogenetic mechanisms in psychogenic tremor. Neurology. 2004; 63(5):812-5. [PubMed: 15365128]

29. Bhatia KP, Bhatt MH, Marsden CD. The causalgia-dystonia syndrome. Brain. 1993; 116(Pt 4): 843-51. [PubMed: 8353711]

30. Espay AJ, Morgante F, Purzner J, et al. Cortical and spinal abnormalities in psychogenic dystonia. Ann Neurol. 2006; 59(5):825-34. [PubMed: 16634038]

31. Benaderette S, Zanotti FP, Apartis E, et al. Psychogenic parkinsonism: a combination of clinical, electrophysiological, and [(123)I]-FP-CIT SPECT scan explorations improves diagnostic accuracy. Mov Disord. 2006; 21(3):310-7. [PubMed: 16211590]

32. Hinson VK, Haren WB. Psychogenic movement disorders. Lancet Neurol. 2006; 5(8):695-700. [PubMed: 16857575]

33. Scherfler C, Schwarz J, Antonini A, et al. Role of DAT-SPECT in the diagnostic work up of parkinsonism. Mov Disord. 2007; 22(9):1229-38. [PubMed: 17486648]

34. Sudarsky L. Psychogenic gait disorders. Semin Neurol. 2006; 26(3):351-6. [PubMed: 16791781]

35. Okun MS, Koehler PJ. Paul Blocq and (psychogenic) astasia abasia. Mov Disord. 2007; 22(10): 1373-8. [PubMed: 17516452]

36. Keane JR. Hysterical gait disorders: 60 cases. Neurology. 1989; 39(4):586-9. [PubMed: 2927686]

37. Lempert T, Brandt T, Dieterich M, et al. How to identify psychogenic disorders of stance and gait. A video study in 37 patients. J Neurol. 1991; 238(3):140-6. [PubMed: 1869889]

38. Baik JS, Lang AE. Gait abnormalities in psychogenic movement disorders. Mov Disord. 2007; 22(3):395-9. [PubMed: 17216648]

39. Monday K, Jankovic J. Psychogenic myoclonus. Neurology. 1993; 43(2):349-52. [PubMed: 8437701]

40. Stone J, Campbell K, Sharma N, et al. What should we call pseudoseizures? The patient's perspective. Seizure. 2003; 12(8):568-72. [PubMed: 14630495]

41. Rosebush, P.; Mazurek, M. The treatment of conversion disorder. In: Hallett, M., editor. Psychogenic movement disorders. Philadelphia: Lippincott Williams \& Wilkins; 2005. p. 289-301.

42. Voon V, Lang AE. Antidepressant treatment outcomes of psychogenic movement disorder. J Clin Psychiatry. 2005; 66(12):1529-34. [PubMed: 16401153] 
43. Rampello L, Raffaele R, Nicoletti G, et al. Hysterical neurosis of the conversion type: therapeutic activity of neuroleptics with different hyperprolactinemic potency. Neuropsychobiology. 1996; 33(4):186-8. [PubMed: 8840341]

44. Marazziti D, Dell'Osso B. Effectiveness of risperidone in psychogenic stiff neck. CNS Spectr. 2005; 10(6):443-4. [PubMed: 15908897]

45. Shapiro AP, Teasell RW. Behavioural interventions in the rehabilitation of acute v. chronic nonorganic (conversion/factitious) motor disorders. Br J Psychiatry. 2004; 185:140-6. [PubMed: 15286065]

46. Ness D. Physical therapy management for conversion disorder: case series. J Neurol Phys Ther. 2007; 31(1):30-9. [PubMed: 17419887]

47. Speed J. Behavioral management of conversion disorder: retrospective study. Arch Phys Med Rehabil. 1996; 77(2):147-54. [PubMed: 8607738]

48. Levy JK, Thomas M. Biofeedback therapy for psychogenic movement disorders. Psychogenic Movement Disorders. 2006:343. [abstract].

49. Moene FC, Spinhoven P, Hoogduin KA, et al. A randomized controlled clinical trial of a hypnosisbased treatment for patients with conversion disorder, motor type. Int J Clin Exp Hypn. 2003; 51(1):29-50. [PubMed: 12825917]

50. Moene FC, Hoogduin KA, Van DR. The inpatient treatment of patients suffering from (motor) conversion symptoms: a description of eight cases. Int J Clin Exp Hypn. 1998; 46(2):171-90. [PubMed: 9558806]

51. Van Nuenen BF, Wohlgemuth M, Wong Chung RE, et al. Acupuncture for psychogenic movement disorders: treatment or diagnostic tool? Mov Disord. 2007; 22(9):1353-5. [PubMed: 17486612]

52. Chastan N, Parain D, Verin E, et al. Psychogenic aphonia: spectacular recovery after motor cortex transcranial magnetic stimulation. J Neurol Neurosurg Psychiatr. 2009; 80(1):94. [PubMed: 19091717]

53. Dafotakis M, Schonfeldt-Lecuona C, Fink GR, et al. [Psychogenic tremor]. Fortschr Neurol Psychiatr. 2008; 76(11):647-54. [in German]. [PubMed: 18988148]

54. Lim EC, Ong BK, Seet RC. Is there a place for placebo in management of psychogenic movement disorders? Ann Acad Med Singap. 2007; 36(3):208-10. [PubMed: 17450268]

55. Feinstein A, Stergiopoulos V, Fine J, et al. Psychiatric outcome in patients with a psychogenic movement disorder: a prospective study. Neuropsychiatry Neuropsychol Behav Neurol. 2001; 14(3):169-76. [PubMed: 11513100]

56. Thomas M, Vuong KD, Jankovic J. Long-term prognosis of patients with psychogenic movement disorders. Parkinsonism Relat Disord. 2006; 12(6):382-7. [PubMed: 16737838]

57. Crimlisk HL, Bhatia K, Cope H, et al. Slater revisited: 6 year follow up study of patients with medically unexplained motor symptoms. BMJ. 1998; 316(7131):582-6. [PubMed: 9518908]

58. Couprie W, Wijdicks EF, Rooijmans HG, et al. Outcome in conversion disorder: a follow up study. J Neurol Neurosurg Psychiatr. 1995; 58(6):750-2. [PubMed: 7608683]

59. Slater ET, Glithero E. A follow-up of patients diagnosed as suffering from "hysteria". J Psychosom Res. 1965; 9(1):9-13. [PubMed: 5857619]

60. Marshall JC, Halligan PW, Fink GR, et al. The functional anatomy of a hysterical paralysis. Cognition. 1997; 64(1):B1-8. [PubMed: 9342933]

61. de Lange FP, Roelofs K, Toni I. Increased self-monitoring during imagined movements in conversion paralysis. Neuropsychologia. 2007; 45(9):2051-8. [PubMed: 17367826]

62. de Lange FP, Roelofs K, Toni I. Motor imagery: a window into the mechanisms and alterations of the motor system. Cortex. 2008; 44(5):494-506. [PubMed: 18387583]

63. Stone J, Zeman A, Simonotto E, et al. FMRI in patients with motor conversion symptoms and controls with simulated weakness. Psychosom Med. 2007; 69(9):961-9. [PubMed: 17991812]

64. Spence SA, Crimlisk HL, Cope H, et al. Discrete neurophysiological correlates in prefrontal cortex during hysterical and feigned disorder of movement. Lancet. 2000; 355(9211):1243-4. [PubMed: 10770312]

65. Vuilleumier P, Chicherio C, Assal F, et al. Functional neuroanatomical correlates of hysterical sensorimotor loss. Brain. 2001; 124(Pt 6):1077-90. [PubMed: 11353724] 
66. Roelofs K, Van Galen GP, Keijsers GP, et al. Motor initiation and execution in patients with conversion paralysis. Acta Psychol (Amst). 2002; 110(1):21-34. [PubMed: 12005227]

67. Roelofs K, Hoogduin KA, Keijsers GP. Motor imagery during hypnotic arm paralysis in high and low hypnotizable subjects. Int J Clin Exp Hypn. 2002; 50(1):51-66. [PubMed: 11783441]

68. Roelofs K, Hoogduin KA, Keijsers GP, et al. Hypnotic susceptibility in patients with conversion disorder. J Abnorm Psychol. 2002; 111(2):390-5. [PubMed: 12003460]

69. Geraldes R, Coelho M, Rosa MM, et al. Abnormal transcranial magnetic stimulation in a patient with presumed psychogenic paralysis. J Neurol Neurosurg Psychiatr. 2008; 79(12):1412-3. [PubMed: 19010957]

70. Ferrara J, Jankovic J. Psychogenic movement disorders in children. Mov Disord. 2008; 23(13): 1875-81. [PubMed: 18709677]

71. Schwingenschuh P, Pont-Sunyer C, Surtees R, et al. Psychogenic movement disorders in children: a report of 15 cases and a review of the literature. Mov Disord. 2008; 23(13):1882-8. [PubMed: 18759366]

72. Hallett M. Psychogenic movement disorders: a crisis for neurology. Curr Neurol Neurosci Rep. 2006; 6(4):269-71. [PubMed: 16822346]

73. Reuber M, Mitchell AJ, Howlett SJ, et al. Functional symptoms in neurology: questions and answers. J Neurol Neurosurg Psychiatr. 2005; 76(3):307-14. [PubMed: 15716517]

74. Stone J, Sharpe M, Rothwell PM, et al. The 12 year prognosis of unilateral functional weakness and sensory disturbance. J Neurol Neurosurg Psychiatry. 2003; 74(5):591-6. [PubMed: 12700300] 


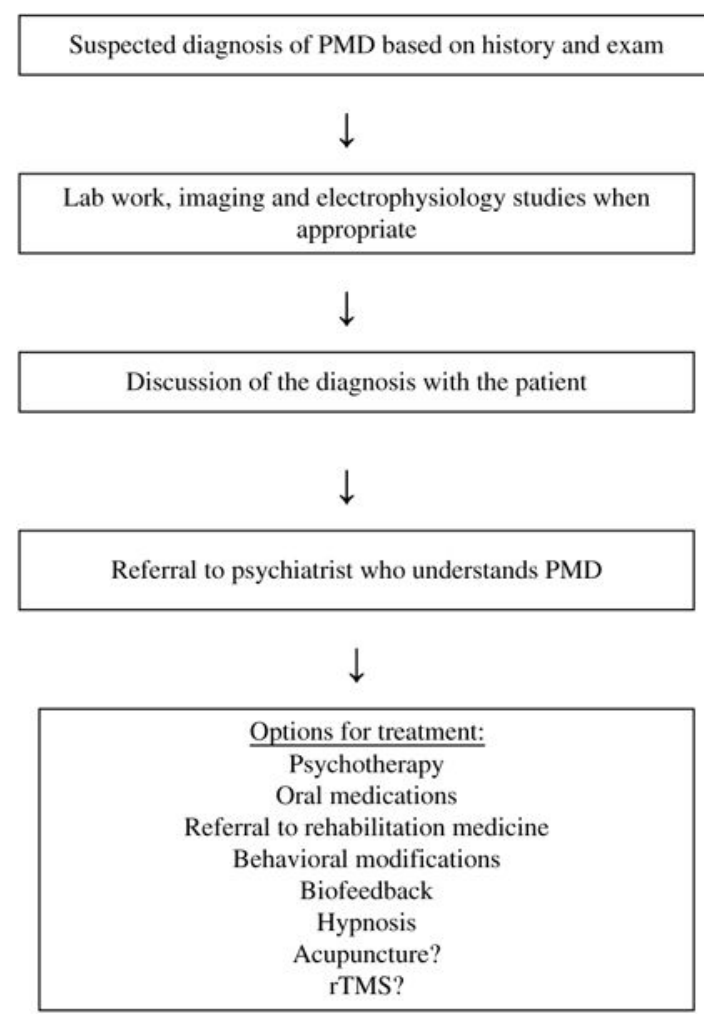

Fig.1.

Algorithm for evaluation and treatment of psychogenic movement disorders. 


\section{Table 1}

\section{Historical characteristics}

\begin{tabular}{|c|c|}
\hline All PMDs & $\begin{array}{ll}\text { - } & \text { Sudden onset } \\
\text { - } & \text { Precipitating event } \\
\text { - } & \text { Spontaneous remission } \\
\text { - } & \text { Multiple somatizations } \\
\text { - } & \text { Litigation or compensation (may suggest malingering) }\end{array}$ \\
\hline PMD tremor & $\begin{array}{l}\text { - Unusual combination of rest, postural, and action tremor } \\
\text { - } \\
\text { Absence of finger tremor }\end{array}$ \\
\hline PMD dystonia & $\begin{array}{ll}\text { - } & \text { Inconsistent dystonic movements over time } \\
\text { - } & \text { Dystonia as a fixed posture or paroxysmal disorder } \\
\text { - } & \text { Incongruous dystonic movements and postures } \\
\text { - } & \text { Other movement disorders also present (bizarre gait) } \\
\text { - } & \text { Foot dystonia in adult } \\
\text { - } & \text { Resting dystonia } \\
\text { - } & \text { Contraction of antagonist with apparent action in agonist } \\
\text { - } & \text { Painful }\end{array}$ \\
\hline PMD myoclonus & $\begin{array}{ll}\text { - } & \text { Inconsistent frequency, amplitude } \\
\text { - } & \text { Involving more than } 1 \text { body region } \\
\text { - } & \text { Remits or improves with distraction } \\
\text { - } & \text { Burst length }>70 \mathrm{~ms} \text { on surface EMG } \\
\text { - } & \text { Triphasic pattern present on agonist/antagonist muscles } \\
\text { - } & \text { Presence of a BP }\end{array}$ \\
\hline PMD Parkinsonism & $\begin{array}{ll}\text { - } & \text { Rest, postural, and action tremor } \\
\text { - } & \text { Passive resistance against examiner rather than true rigidity } \\
\text { - } & \text { Non-decremental response on rapid alternating movements } \\
\text { - } & \text { Effortful response to tasks marked by grimacing, sighing } \\
\text { - } & \text { Bizarre response to postural testing, overexaggeration without falling }\end{array}$ \\
\hline PMD gait & $\begin{array}{ll}\text { - } & \text { Momentary fluctuation of gait and stance } \\
\text { - } & \text { Excessive slowness } \\
\text { - } & \text { Psychogenic Rhomberg } \\
\text { - } & \text { Uneconomic postures } \\
\text { - } & \text { Walking on ice } \\
\text { - } & \text { Sudden buckling of knees without falling }\end{array}$ \\
\hline
\end{tabular}

Data from Refs. $1,2,5,8,11,13,20,22,24,37,39,73$ 


\section{Table 2}

Electrophysiology characteristics of psychogenic tremor

\begin{tabular}{|lllll|}
\hline Tremor Characteristic & PMD & ET & PD & $\begin{array}{l}\text { Normal } \\
\text { Volunteer } \\
\text { (Mimic Tremor) }\end{array}$ \\
\hline Amplitude & Variable & Stable & Stable & No data \\
\hline Frequency & Variable $(4-10 \mathrm{~Hz})$ & $4-12 \mathrm{~Hz}$ & $4-6 \mathrm{~Hz}$ & No data \\
\hline Distractible & Yes & No & No & Yes \\
\hline Weighting & $\begin{array}{l}\text { Increased amplitude or stays } \\
\text { the same }\end{array}$ & $\begin{array}{l}\text { Amplitude stays the same or } \\
\text { decreased }\end{array}$ & $\begin{array}{l}\text { Amplitude stays the same } \\
\text { or decreased }\end{array}$ & No data \\
\hline Entrainment & $\begin{array}{l}\text { Yes, tremor entrains or } \\
\text { disappears in many (but not all) }\end{array}$ & No & No & No data \\
\hline cases & Fewer affected & Multiple, asymmetric & Multiple, symmetric & No data \\
\hline Oscillators & Single & Multiple & Multiple & Single \\
\hline Ballistic movement test & $\begin{array}{l}\text { Cessation of tremor or } \\
\text { decreased amplitude }\end{array}$ & No cessation of tremor & No cessation of tremor & $\begin{array}{l}\text { Cessation of } \\
\text { tremor or } \\
\text { decreased } \\
\text { amplitude }\end{array}$ \\
\hline
\end{tabular}

Data from Refs. ${ }^{15-19,27}$ 
Table 3

\begin{tabular}{|c|c|}
\hline Favorable & Poor \\
\hline - Short duration of symptoms $(<1 \mathrm{y})$ & - Chronic symptoms \\
\hline - Inconsistency of movements & - Motor symptoms \\
\hline - Good physical health & - Smoking \\
\hline - Positive social life perception & - Suggestibility \\
\hline - Elimination of stressor & - Pending litigation \\
\hline - Patient's perception of receiving effective treatment & - Dissatisfaction with physician \\
\hline - Changed marital status & - Older age at onset of symptoms \\
\hline - If admitted to hospital, resolution of symptoms on discharge & - \\
\hline
\end{tabular}

Data from Refs. $55,56,58,74$ 